\title{
Differences between how Undergraduate Students Define Geometric Solids and what their Lecturers Expect from them through the Lens of the Theory of Commognition
}

\author{
Verónica Martín-Molina ${ }^{1 *}$, Alfonso J. González-Regaña ${ }^{1}$, Rocío Toscano ${ }^{1}$, \\ José María Gavilán-Izquierdo ${ }^{1}$ \\ 1 Departamento de Didáctica de las Matemáticas, Universidad de Sevilla, SPAIN
}

Received 17 May $2020 \cdot$ Accepted 7 September 2020

\begin{abstract}
Undergraduate students' engagement with mathematical discourse when defining geometric solids is analysed and compared with what their lecturers expect them to do. The theory of commognition is adopted as the theoretical framework, which permits the characterisation and comparison of their discursive activities, and may lead to the identification of potential commognitive conflicts. The participants were forty-five undergraduate students (primary preservice teachers) and their lecturers. A worksheet with questions about defining geometric solids was used as a data collection instrument. The students, in small groups, had to discuss and write their answers, and the lecturers were asked what they expected from their students. Results show three main areas of mismatch between students' engagement in mathematical discourse and what their lecturers expected from them. There is no clear consensus across the students on how to define or on what a definition is or on which criterion to use when selecting a definition.
\end{abstract}

Keywords: defining, mathematical discourse, theory of commognition, undergraduate students

\section{INTRODUCTION}

In the last years, research at university level in the field of mathematics education has been the focus of interest of many studies and it has increased its presence in specific journals like the International Journal of Research in Undergraduate Mathematics Education (IJRUME) and the journal Problems, Resources, and Issues in Mathematics Undergraduate Studies (PRIMUS). Moreover, this research area has also been the focus of several specific conferences like the Research in Undergraduate Mathematics Education Conference in the United States (RUME) and the International Network for Didactic Research in University Mathematics (INDRUM), and it has gained an important presence in general mathematics education conferences (Biza et al., 2016).

In particular, research in mathematical practices, such as proving, conjecturing, defining, modelling, etc., has been a relevant topic in undergraduate mathematics education research (Viirman \& Nardi, 2019; Weber \& Mejia-Ramos, 2013). In this paper, the focus is on the practice of defining, whose importance has been highlighted by several authors. For instance, Freudenthal (1973) stated that defining "can be an essential feat, more essential than finding a proposition or a proof" (p. 134) and de Villiers (1998) pointed out that

The construction of definitions (defining) is a mathematical activity of no less importance than other processes such as solving problems, making conjectures, generalizing, specializing, proving, etc., and it is therefore strange that it has been neglected in most mathematics teaching. (p. 249)

In recent years, there have been several authors that have studied the mathematical practice of defining at university level. Among others, Ouvrier-Buffet (2011) characterised the process of construction of a mathematical definition that is linked to the mathematical practice of proving. Furthermore, Zandieh and Rasmussen (2010) created a framework called defining as a mathematical activity (DMA) in order to explain how students learn to create and use mathematical definitions in class. Other authors like Tabach and Nachlieli (2015) focused on how

(c) $\mathbf{2 0 2 0}$ by the authors; licensee Modestum. This article is an open access article distributed under the terms and conditions of the Creative Commons Attribution License (http://creativecommons.org/licenses/by/4.0/).

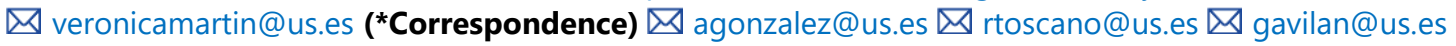




\section{Contribution to the literature}

- This paper shows how to employ the theory of commognition to characterise students' discursive activity when defining and what their lecturers expect from them. This allows their comparison in order to identify similarities and differences.

- The participants of the study were 45 undergraduate students, pre-service teachers enrolled in an undergraduate degree in Primary Education, and two of their mathematics lecturers. Qualitative methods were employed to study their discursive activity.

- Results show that, when describing the solids, defining them and selecting the best definition, there are differences between students' engagement in mathematical discourse and what their lecturers expected from them.

undergraduate students use the mathematical definition of a function. Moreover, Martín-Molina et al. (2018) characterised how professional mathematicians construct new definitions by generalizing other existing ones.

According to Rasmussen et al. (2005), symbolising, algorithmatising, and defining activities (among others) are social or cultural practices. Following this characterization of defining as a sociocultural practice, a sociocultural approach is adopted in this work when studying how undergraduate students construct definitions: Sfard's (2008) theory of commognition. This theory (also called commognitive framework) considers the discourse as the principal object of attention, which "sets this approach apart from other types of participationists' research" (Sfard, 2008, p. 275). This framework has shown its relevance to research at university level (for instance, Heyd-Metzuyanim et al., 2015; Ioannou, 2018; Nardi et al., 2014; Toscano et al., 2019) and has been used to compare students' and lecturers' engagement in discursive activities (Güçler, 2013; Stadler, 2011; Thoma \& Nardi, 2016, 2018). There have also been several studies that focus on the practice of defining among undergraduate students (Fernández-León et al., 2019; Gavilán-Izquierdo et al., 2019; Sánchez \& García, 2014). It is less common to study the differences between undergraduate students' discursive activity when defining and what their lectures expect to see in their students' responses.

In this paper, undergraduate students' discursive activity when defining geometric solids is analysed in order to compare it with what their lecturers expect them to do.

\section{THEORETICAL FRAMEWORK}

The theory of commognition (combination of the terms communication and cognition) is not a mere replacement of cognition with another different theory because "commognitive research differs from both its predecessors, behaviourism and cognitivism, in its epistemology, ontology, and methods" (Sfard, 2008, p. 275). The discourse becomes the main object of interest, which makes this approach different from other types of sociocultural approaches. Sfard (2008) defines a discourse as a particular way of communication that can be characterised through certain properties (the objects and visual mediators that are used and the rules that the participants follow in their communication).

Since Sfard (2008) also states that the different discourses can be distinguished by the specification of the particular objects present in them, the mathematical discourse will be the discourse that deals with the mathematical objects such as arithmetic operations, equations, groups, or prisms. Furthermore, Sfard (2008) also distinguishes between object-level discourse, which is a discourse about objects, and meta-level discourse, which is a discourse about another discourse. For example, discussions about what a geometric solid is would be at object level and discussions about what a definition is or how to construct a definition that fits a geometric solid is at meta level.

In order to characterise the mathematical discourse, Sfard (2008) proposes four properties: word use, visual mediators, narratives and routines. Word use is important because one of the distinctive characteristics of discourses is the keywords that they use. These words include both mathematical terms like polygon and ordinary words used with a mathematical meaning, like leaning to mean oblique. Furthermore, "visual mediators are means with which participants of discourses identify the object of their talk and coordinate their communication" (Sfard, 2007, p. 571). Therefore, visual mediators are objects such as graphs of functions, algebraic expressions in equations or in functions, images of geometric figures, figures in dynamic mathematics software, etc.

Narratives are defined as "any sequence of utterances, spoken or written, framed as a description of objects, of relations between objects, or of activities with or by objects" (Sfard, 2008, p. 223). Narratives can be accepted or rejected by the discursants; those narratives that are accepted are called endorsed narratives. Examples of endorsed narratives in the mathematical discourse are definitions, axioms or theorems. Finally, for Sfard (2008), routines are repetitive patterns that characterise the activities of the discursants, for instance, how they define mathematical objects, prove propositions and theorems, solve equations, etc. 
Moreover, Sfard (2008) considers learning mathematics as a change in the discourse, which can be seen as a change in any of the four properties mentioned above. A possible source of learning is the resolution of a commognitive conflict, which "is defined as the phenomenon that occurs when seemingly conflicting narratives come from different discourses-from discourses that differ in their use of words, in the rules of substantiation, and so on" (Sfard, 2007, p. 575).

Several authors point out that routines can play an important role in characterising learning (Lavie et al., 2019). Furthermore, Cooper and Karsenty (2018) state that these four discursive properties permit them to compare the patterns of communication of different communities (in their study, lecturers and mathematicians). In this paper, those properties are used in the characterisation of students' discursive activity when defining geometric solids, and in the discursive activity that their lecturers expect from them. This permits their comparison in order to identify similarities and differences, which could indicate potential commognitive conflicts.

\section{METHODOLOGY}

This section contains the participants and context, the data collection instrument and how the data collection and analysis were carried out. A qualitative method was employed.

\section{Participants and Context}

There were two sets of participants: undergraduate students and their lecturers. The student participants were 45 pre-service teachers that were enrolled in an undergraduate degree in Primary Education in a big public university of Spain. These students (18-19 years old) had a compulsory subject on mathematics on their first year of their undergraduate degree. Once a week, they worked for an hour in mixed-gender groups of three to four students while they tried to solve a variation of mathematical problems and tasks. Specifically, 12 groups of students participated in this study, called G1,..., G12. The students of each group were called S1, S2, S3 and S4, without specifying their group in the notation, since the group is always mentioned when referring to them. Groups G1, ..., G6 had a lecturer that was different from that of groups G7, ..., G12, but all of them had been taught the same topics using the same slides and problem worksheets because both lecturers had agreed on what to teach and how to do it. Both lecturers had a Ph.D. in mathematics and more than five years of experience in teaching mathematics and mathematics education at university level. They were members of a department of mathematics education.

\section{Data Collection Instrument}

A specific mathematics field (geometry, analysis, statistics, etc.) was needed in order to study the process of defining among undergraduate students. The choice was made to focus on 3D geometry because it provides a very rich field in which defining and definition plays an important role and it is a continuation of previous studies on how students define in 2D geometry (Escudero et al., 2014; Sánchez \& García, 2014). Moreover, students are not as familiar with 3D geometry as with 2D geometry, which forces them to discuss how to construct definitions instead of reciting the definitions they already know.

The data collection instrument had to facilitate or promote the generation of discussion because, in the theory of commognition, the data are "human talk, either vocal or written" (Sfard, 2008, p. 277). This can mean the inclusion of open questions that promote discussion.

Taking into account all these ideas, a worksheet was designed by adapting one that had been used in previous studies (Escudero et al., 2014; Sánchez \& García, 2014, which were in turn based on Gavilán et al., 2002). The aim of the worksheet was to characterise how undergraduate students construct definitions that fit given solids (3D geometric objects with certain properties). This worksheet has been validated as a data collection instrument in previous publications (Fernández-León et al., 2019; Gavilán-Izquierdo et al., 2019).

A discussion of why each of the questions of the worksheet was created (and why they were ordered as they were) is included below, mentioning the influence of previous work in the design. Since the original research was conducted in Spanish, both the worksheet and the participants' responses have been translated into English.

The previous worksheet, in Escudero et al. (2014) and Sánchez and García (2014), contained pictures of three quadrilaterals: a square, a rectangle and a rhombus. These quadrilaterals were chosen because they had some common properties (four sides, parallel sides) and some properties that differentiated each one from the others (the square was the only regular quadrilateral, the rectangle was the only one that did not have four equal sides and the rhombus was the only one that did not have four equal angles). The current worksheet contains pictures of three prisms: a cube, a parallelepiped that is not a cube, and a prism with a concave base (see Figure 1). Three solids (instead of only one) appear in order to promote the presence of repetitive patterns when students engage in mathematical discourse. Moreover, these particular solids were also chosen because all three of them have some properties in common (they are prisms with a four-sided base, for example) and other properties that differentiate them from the other solids 


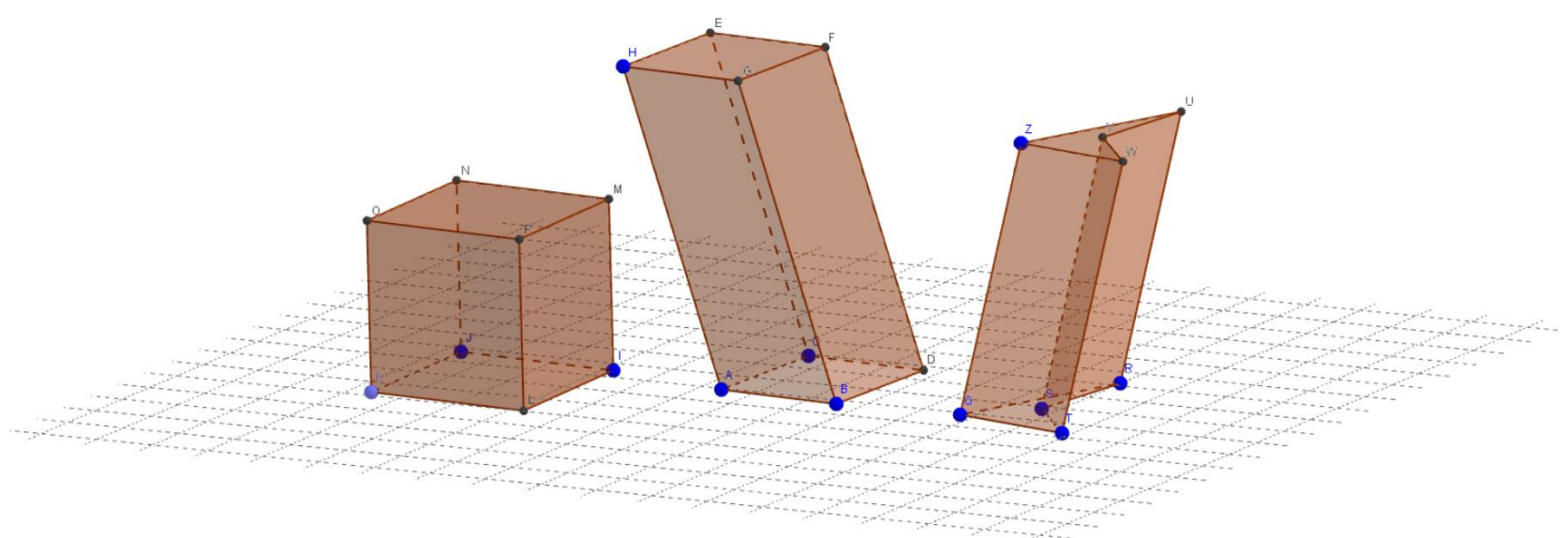

Figure 1. The picture of the solids that appear in the worksheet (Gavilán-Izquierdo et al., 2019)

(the first solid is the only regular prism, the second solid is the only one that is an oblique parallelepiped and the third one is the only one which is concave). The pictures were designed using the dynamic geometry software GeoGebra (Hohenwarter et al., 2018).

In order to design the questions of the worksheet, it was taken into account that, for us, the process of defining is the one that begins with the identification and description of the characteristics of objects and ends with the construction of a formal mathematical definition. Therefore, as in the previous worksheet (Escudero et al., 2014; Sánchez \& García, 2014), the first four questions concern the identification and study of properties of the solids:

1. In the 3 previous solids you can identify basic elements like faces, vertices, edges, etc. What properties or characteristics of these elements can you observe in each solid?

2. Among the above properties or characteristics, can you identify the ones that only two solids have in common?

3. Among the properties or characteristics of question 1 , can you identify any property that the three solids have in common?

4. Is there any property of any of the solids that differentiates it from the other two?

In the first question, the students should talk about the properties of the solids, like the regularity, convexity or parallelism of the faces, how many faces, vertices or edges there are, etc. In the wording of the question, the words properties and characteristics are used as synonyms. The reason for giving both words is that the students came from different backgrounds, so it was not known which one they had used previously.

In questions 2 to 4 , the students have to compare and contrast the properties of the solids that they identified previously. In order to do that, they are asked to identify the properties that only two solids have in common (question 2), the ones that all three solids have in common (question 3) and which properties differentiate one solid from the other two (question 4).

All the previous questions prepare the students for the next two, which are similar to the ones that appeared in the previous worksheet (Escudero et al., 2014; Sánchez \& García, 2014):
5. Define each of these solids.
6. Can you give another definition of any of the solids?

In question 5, the students should construct a definition of each of the solids, in order to see which of the previous properties appear and/or are deemed important and which ones are discarded. This may generate a discussion among students about what a definition is. Question 6 is intended to promote discussion about how to construct more than one definition for a particular solid. This will lead the students to handle more than one definition (and to discuss if they are equivalent or not), which is useful for the next questions:

7. Is one of your definitions valid for another solid too? For example, is the definition of solid 1 also valid for solids 2 or 3 ?

8. Could you give a definition that is valid for two of the solids? And for 3 ?

Questions 7 and 8 were included to generate a discussion about inclusive and exclusive definitions and how to construct them. Exclusive definitions are those that define a partition, that is, a classification of geometric objects into categories such that each object belongs to only one category. Inclusive definitions permit an object to belong to more than one category. For instance, when working with quadrilaterals, an inclusive definition of rectangle would regard a square as a rectangle, whereas an exclusive definition would not. In the current worksheet, questions 7 and 8 were designed to enquire into the ideas that the students have about the appropriateness of a definition, since some of them think that a definition that is valid for two solids is not really correct. 
Table 1. Analysis of the part of the first question concerning the second solid

\begin{tabular}{ll}
$\begin{array}{l}\text { Expected narratives when describing the } \\
\text { second solid in question } \mathbf{1}\end{array}$ & Groups which gave that answer \\
\hline All the opposite faces are equal, and parallel & $\mathrm{G} 1(1.38, \mathrm{~W}), \mathrm{G} 4(1.34), \mathrm{G} 7(1.83-85, \mathrm{~W})$ \\
Some angles are acute and some obtuse & $\mathrm{G} 7(1.110,135, \mathrm{~W}), \mathrm{G} 8(1.25, \mathrm{~W})$ \\
Opposite faces are equal & $\mathrm{G} 1(1.36), \mathrm{G} 5(1.29, \mathrm{~W})$ \\
Opposite faces/Bases are equal & $\mathrm{G} 8(1.69), \mathrm{G} 11(1.92, \mathrm{~W}), \mathrm{G} 12(1.117,121, \mathrm{~W})$ \\
It has 6 faces, 12 edges and 8 vertices & $\mathrm{G} 1(1.53-54-\mathrm{only}$ edges, W-vertices and edges), G2(1.4, W), G3(1.15-20, W), G4(1.8- \\
& $22, \mathrm{~W}), \mathrm{G} 5(1.27, \mathrm{~W}), \mathrm{G} 6(1.13-17$, faces and edges, W-all), G7(1.19,88-89,103-104,W), \\
& $\mathrm{G} 8(1.14-16, \mathrm{~W}), \mathrm{G} 9(1.44,61-\mathrm{faces}$ and edges, W-all), G10(1.30,32,37,W), G11(1.67,84- \\
It is oblique/not right & $85,88, \mathrm{~W}), \mathrm{G} 12(1.117,128-131,133-134, \mathrm{~W})$ \\
It is a prism & $\mathrm{G} 7(1.86), \mathrm{G} 8(1.18)$ \\
It is a parallelepiped & $\mathrm{G} 1(1.27, \mathrm{~W}), \mathrm{G} 4(1.7), \mathrm{G} 8(1.2-3), \mathrm{G} 12(1.86, \mathrm{~W})$ \\
It is a convex polyhedron & None \\
It is a hexahedron & None \\
Unexpected narratives & None \\
It is a parallelogram & \\
\hline
\end{tabular}

Finally, in question 9, which was not included in the previous worksheet (Escudero et al., 2014; Sánchez \& García, 2014), the students have to make explicit their criteria for choosing between the two definitions that they gave in questions 5 and 6:

9. Of the two definitions that you have given for each solid in questions 5 and 6, which one would you choose? Why?

\section{Data Collection}

The 45 student participants (divided in groups G1,..., G12) were observed during a one-hour session. All the groups of students were provided with a copy of the worksheet and were instructed to answer the questions in it, verbalizing their answers as much as possible and writing them down. Their discussion was audio recorded and their written answers collected.

On the other hand, there was a meeting between the research team and the two lecturers that were the instructors of the above-mentioned students. The lecturers were asked what responses they expected from their students. Researchers took detailed notes of the lecturers' expected answers to each question and the lecturers also wrote down the answers they expected in a copy of the worksheet.

\section{Analysis}

Once all the audio recordings of the students were transcribed, the answers expected by the lecturers and the students' discussion and written responses were analysed in order to compare them. This analysis was carried out by first identifying the properties of the mathematical discourse (Sfard, 2008). Each of the authors of this paper analysed the data individually in order to identify these properties, later compared those in pairs and finally the whole group discussed the results until a consensus was reached. Neither the lecturers nor the students mentioned explicitly the words narratives or routines in their discussions or written responses, but they were inferred by the researchers from those discussions and responses.

For each group of students, if the narratives, visual mediators or mathematical words that the lecturers expected appeared, it was noted if there were in the transcripts (including the transcript line), in the written answers or in both. Moreover, it was written down if the groups' narratives were completely or only partially identical to the expected narratives. If the narratives were not the expected ones, they were gathered in order to be classified, and it was checked if they appeared in the discursive activity of other groups. Once all those properties were identified, a search for patterns in the discussions and responses (from which routines can be inferred) was performed.

An example of the analysis of part of the first question appears in Table 1. The left column has the narratives that the lecturers expected and, at the bottom, one they did not expect, but which appeared more than once in the students' discussions or written responses. The narratives that are partially crossed out mean that, when analysing the students' answers, there appeared narratives without that part. The right column has the groups in which the narratives have been identified (with the transcript line numbers in parentheses and a $W$ if the answer appears in the written document too). In the narrative "it has 6 faces, 12 edges and 8 vertices", some groups did not quantify all the elements, only one or two. This information is included in parentheses.

In question 1, when describing the three solids, the narrative "it has 6 faces, 12 edges and 8 vertices" often appeared at the beginning of the description of all three solids, thus leading to the inference of a routine which consists in quantifying the elements of a solid when asked to describe them. This routine coincides with one of the routines that the lecturers expected. 


\section{RESULTS}

In this section, some of the students' discussion and written responses are described and compared with the answers that their lecturers had expected. Since, for us, the process of defining is the one that begins with the identification and description of the characteristics of objects, continues with the construction of several preliminary definitions and ends with the selection of one of them, which will become the formal mathematical definition, the results have been organized around three themes: how students describe the solids, how they construct definitions for them and how they choose what they consider the best definition. Students' and lecturers' discursive activity around these three themes is described in terms of the discursive properties of Sfard's (2008) commognitive framework: word use, narratives and routines. No visual mediators are mentioned because almost none appeared apart from those in the worksheet (Figure 1). Students' discursive activity was at meta level when students discussed what a definition is or how to choose the best definition but was at object level when they discussed the characteristics of a particular solid, for example.

\section{Some Characteristics of How Students Describe}

When asked to describe the elements of the solids, the lecturers expected narratives related to their number ("it has 6 faces, 12 edges and 8 vertices") or to their other properties ("all the faces are squares (and equal)", "all the faces are equal", "all its edges are equal", "all its angles are right"). Moreover, although the first four questions ask about the elements of the solids, the lecturers also expected that some students would describe the solids themselves, by giving them a label or naming one of their properties ("it is regular", "it is a cube", "it is a hexahedron", "it is a prism", "it is convex").

Students did use all these three types of narratives in their discussions and written responses, but there were some differences in their word use and routines. Indeed, students' mathematical vocabulary was quite limited, which led them to omit references to some properties of the faces (like their convexity/concavity) or to use other words from the colloquial discourse with mathematical meaning when describing the solids or their elements (like leaning instead of oblique). For instance, a student of group G8 stated "that is why I say that I see it as leaning a bit, so it is leaning". The mismatch between the students' word use and their lecturers' expected word use was especially noticeable in the case of the solids that the students seemed to be less familiar with, that is, the solids that were not prototypical.

Concerning students' routines, it seems that the students considered that they had to begin their description of the elements of the solids by first counting how many faces, edges and vertices there were. This is supported by the appearance of the narrative "it has 6 faces, 12 edges and 8 vertices" (or a variation of it) in the discussions of all the groups when describing the elements of the three solids. Moreover, when describing the elements of the third solid, all the groups quantified them, but two groups did not add any qualitative properties (G6, G10) and other groups added very few properties (groups G2 and G9 added "only the bases are equal" and G3 said that "the edges are not equal").

Finally, it is worth highlighting that some groups of students decided to give a definition as an answer to question 1, when they had been asked to merely describe the elements of the solids. This led some students to state that the answer to question 5 (in which they were asked to construct definitions of the solids) should be the same answer that they had given in question 1 (in which they had been asked to describe the elements of the solids). For instance, group G11 had the following discussion:

295: S4: And now to define.

296: S3: [...] We already did it.

$[\ldots]$

299: S1: What happens is that we have to define... we have to define a solid with all the characteristics that we said before. I think.

[...]

308: S4: Then... It is the same again.

309: S2: What?

310: S4: I mean, to write the same thing again.

After that, they decided to write as an answer to question 5: "the definitions are in question 1 ".

\section{There is no Consensus across the Students of a Group or across the Groups on How to Define}

The lecturers expected the students to always use the same routine when defining the solids in questions 5 and 6. Indeed, they expected the students to construct definitions containing a label and some (or all) of the properties that they had identified in previous questions. Therefore, they expected definitions such as "solid 1 is a solid that has all square faces" or "solid 2 is a prism with 6 faces that are parallelograms" and that the students would merely add or change some of the properties of their first definition when they needed another one.

Although ten groups (all except G3 and G4) used this routine, the students also used two others. One of them, used by seven of the twelve groups of students (G2, G3, G4, G5, G6, G10, G11), consisted in defining the solids by using narratives mentioning only properties, with no label. For example, group G4 defined the first solid by 
writing "solid 1: all the faces are equal, squares. All [solids] have 6 faces, 12 edges and 8 vertices" and G10 by "solid 1: all its angles are right and its height is equal in all its sides". Moreover, group G2 defined the second solid by writing "solid 2: it has 6 faces, 12 edges and 8 vertices with equal square bases and its 4 sides are equal, rectangles".

The other unpredicted by the lecturers' routine consisted in defining the solids by employing only a label and, at most, an adjective (groups G4, G5, G9). For instance, group G5 stated that solid 3 was an "irregular prism", without adding any more properties. During their discussion, a student of G4 summed up their response the following way: "solid 1 could be [a] cube, solid 2 [is a] rectangular prism and solid 3 is an irregular prism".

Some of the groups did something surprising: they employed more than one routine to construct a definition. While there were four groups that always defined by labelling and adding properties (G1, G7, G8, G12) and there was another one that defined by only properties (G3), the other seven groups employed more than one routine. Indeed, six groups used two routines when trying to define the solids and one group (G5) employed the three routines mentioned above. For example, G4 defined solid 1 in question 5 by giving a list of properties ("All the faces are equal, squares. All [solids] have 6 faces, 12 edges and 8 vertices"), while in question 6 they wrote down simply "cube". Three groups, G2, G6, G10, gave definitions with labels and properties in question 5, then decided to only use properties in question 6. In the discussion of G11, they mentioned definitions with only properties but they decided to write down definitions with labels and properties. Group G9, when discussing questions 5 and 6 , employed both definitions with only a label (like one student who said during their discussion "number one is a cube") and definitions with a label and properties:

195: S2: It is a cube with 6 faces, with...

196: S1: A cube, a cube with 6 faces. I should put the edges, shouldn't I? How many?

\section{$[\ldots]$}

199: S1: 8 vertices and 12 edges.

200: S3: The same in the other one.

203: S4: All of them have 6 faces, the same edges.

204: S1: And I should write what we wrote here, four rectangular faces, two square faces.

205: S2: We have really written the same.
This excerpt shows that the students of this group, who had begun by giving only a label to solid 1, decided to construct a definition with a label (cube) and all the properties that they had mentioned in the first question of the worksheet. That is the definition that they wrote as answer to question 5 ("solid 1 is a cube with 6 equal faces, 8 vertices and 12 edges") and they left question 6 unanswered.

Therefore, many groups did not seem to have a regular pattern when constructing a definition and some groups of students did not seem to have a clear idea of what defining is. For example, in some of the groups, a meta-level discussion about what a definition is and how to define arose. This produced many interesting narratives, like what a student of group G7 answered when asked what he considered a definition to be: "the name and... the characteristics... is the definition". Another student of the same group agreed with that statement and a third one added "[the definition] has to be only for that [solid]". These discussions may have been caused by a lack of explicit instruction about what a definition is and how to construct it.

Finally, it is noticeable that, when asked to give another definition for each solid, three of the groups (G1, G7, G9) either explicitly said narratives of the type "we do not know another definition" or did not answer the question. Two other groups (G3, G8) gave an alternative definition for one or two solids but not for all three.

\section{There is no Consensus across the Groups on which Definition is the Best Definition}

In the last question, the students were asked which definition they would choose among the two that they had given in previous questions. The lecturers expected that the groups of students would employ a routine that consists in choosing the definition that had the highest number of properties, i.e., the most complete. This would mean that they would choose the definition that had been constructed by including a label and all the characteristics of the solid that they knew.

Four of the groups (G1, G3, G7, G9) did not answer the last question of the worksheet (in the case of G1, G7 and G9, because they had not given two definitions in the previous questions). Therefore, there is not enough evidence to determine which criteria these groups would employ when choosing a definition. Among the other eight groups, one group of students, G8, gave two definitions for the first solid, but not for the other two. The students of this group chose the first definition they had given because they said that it was "the one we know and the one that we think defines the most [sic]". Four other groups (G2, G5, G10, G11) chose a definition because it was the "most complete". For example, the students of group G10 had the following discussion when answering question 9:

212: S3: The one in [question] 5 is better, isn't it? 
213: S2: Yes, the first one, because here it speaks of angles and here it speaks of angles, sides and faces. And of the [definitions for solid] two, the same, here we only speak of the angles.

\section{4: S1: And there of everything.}

215: S2: No, and here we only speak of the faces. I would choose the first one.

Whereas, students of G11 justified their choice of definition in the same question by saying:

455: S4: This definition [the one in question 5] instead of the one we gave here [the one in question 6].

456: S1: Because it is more complete.

457: S3: Huh, right, here [in question 5] we have completed it more.

458: S4: We have chosen this definition because it is the most complete.

There were also two groups (G6, G12) that chose the first definition that they had given. Indeed, the students of G12 wrote "we had a clearer idea at the beginning and [the first definition] was much more elaborate, the second one was more spontaneous and improvised". Finally, there was a group (G4) that had constructed two definitions for each solid, one with only characteristics of the solid and another one with only a label. This group decided to employ an unexpected routine, they chose the definition that only had a label because they considered that it was the "most correct". Indeed, student S3 stated that they should choose the definition of question 6 because "we know it is the most correct, we know that it is a cube and a prism, isn't it?".

To sum up, there does not seem to be a consensus across groups about which criterion to use when choosing a definition. Among the eight groups which answered the question about the selection of a definition, four groups decided to choose the most complete one and the rest of the groups employed other routines.

\section{CONCLUSIONS AND DISCUSSION}

Our study has identified three main areas of mismatch between how students engaged in discursive activity when defining geometric solids and what their lecturers expected from them, which could generate commognitive conflicts. The first mismatch appeared when the students described the properties of the solids: while the lecturers expected the students to label or name some properties, some students only quantified elements of the solids. The second mismatch occurred when the students defined the solids. Here, the lecturers expected the students to give a label followed by a list of properties, but the students defined using three different ways: labelling, giving a list of properties or doing both of them. The third mismatch appeared when the students selected the best definition. In this case, the lecturers expected that students would choose the definition that had the highest number of properties. Nevertheless, some groups of students only gave one definition of the solids and the rest of the groups did not follow a consistent criterion. Thus, our research offers a better insight into students' engagement with activities such as the identification of properties and the construction of definitions for solids. Moreover, this study complements the article by Fernández-León et al. (2019), where the authors show some commognitive conflicts that occur because of differences among students' discursive activities. While in the previous article the focus was on students' engagement with describing and defining activities, in this study there is also a comparison between that engagement and what their lecturers expect from them.

According to the theory of commognition, there is a difference between object-level and meta-level discourse (Sfard, 2008). At object level, the students managed to describe and establish links between the solids that appeared in the data collection instrument. However, the words that they used were sometimes very informal, not part of the literate discourse that they should be able to use at university. At meta level, the students had some problems when asked to construct a definition, compare it with others and consider the existence of different definitions for a solid. On the other hand, their lecturers were mathematicians and, as Tabach and Nachlieli (2015) highlight, "in the mathematical community, mathematical definitions are precise definitions that contain necessary and sufficient conditions to help us determine whether or not a word applies to certain examples" (p. 167). Therefore, the results have provided information about how far or near the students' discursive activity is from the discursive activity that their lecturers expected from them. This could help their lecturers to adapt their teaching in order to close the gap between them. Moreover, since the student participants of this study were prospective mathematics teachers, this could help to improve teaching at both university and schools.

The results of the study show that it is necessary to make explicit in mathematics education the process of defining, a process that sometimes seems to be transparent. This would include discussing both the optional and imperative features of definitions that Zaslavsky and Shir (2005) mention (for example, it is imperative that all definitions must be noncontradicting and unambiguous). This instruction would also include discussing the relations between definitions (equivalence, inclusivity, etc.). This explicit teaching about the process of defining should be part of the 
mathematics instruction that every pre-service teacher receives. Indeed, we believe that this should be part of mathematics instruction at every level of mathematics education. However, how to accomplish this is still an ongoing debate and it is worth studying.

Therefore, the theory of commognition has permitted the comparison of students' discursive activity and what their lectures expect from them, which in turn has shown that both students and lecturers differ in their use of words and in how they decide if a narrative should be endorsed when describing, defining and selecting definitions. This is another argument for the need for instruction about the process of defining and for the need for research on how to do it properly.

Finally, we acknowledge some limitations of our study. Firstly, the fact that the students' discussions were audio recorded instead of video recorded means that some information about students' nonverbal communication has been lost. Secondly, the way in which the solids were constructed using GeoGebra (Hohenwarter et al., 2018) made some vertices seem bigger than others, and this may have generated confusion among some the students (although there does not seem to be any evidence of this confusion in our data). Despite the limitations of our study and the difficulties of making the commognitive framework operative, this study has permitted us to identify important issues that may have been overlooked otherwise.

\section{ACKNOWLEDGEMENTS}

All the authors were partially supported by the "VI Plan Propio de Investigación y Transferencia" of the Universidad de Sevilla (Spain) and by the Research Group in Mathematics Education FQM-226 of the Junta de Andalucía (Spain).

\section{REFERENCES}

Biza, I., Giraldo, V., Hochmuth, R., Khakbaz, A., \& Rasmussen, C. (2016). Research on teaching and learning mathematics at the tertiary level: State-of-theart and looking ahead. Springer. https: / / doi.org/10.1007/978-3-319-41814-8

Cooper, J., \& Karsenty, R. (2018). Can teachers and mathematicians communicate productively? The case of division with remainder. Journal of Mathematics Teacher Education, 21(3), 237-261. https: / / doi.org/10.1007/s10857-016-9358-7

De Villiers, M. (1998). To teach definition or to teach to define? In A. Olivier \& K. Newstead (Eds.), Proceedings of the 22th Conference of the International Group for the Psychology of Mathematics Education (Vol. 2, pp. 248-255). PME.

Escudero, I., Gavilán, J. M., \& Sánchez-Matamoros, G. (2014). Una aproximación a los cambios en el discurso matemático generados en el proceso de definir [An approach to changes in the mathematical discourse generated in the process of defining]. Revista Latinoamericana de Investigación en Matemática Educativa, 17(1), 7-32. https:/ / doi.org/10.1080/14794802.2014.918338

Fernández-León, A., Gavilán-Izquierdo, J. M., GonzálezRegaña, A. J., Martín-Molina, V., \& Toscano, R. (2019). Identifying routines in the discourse of undergraduate students when defining. Mathematics Education Research Journal. https:/ / doi.org/10.1007/s13394-019-00301-1

Freudenthal, H. (1973). Mathematics as an educational task. Reidel. https:/ / doi.org/10.1007/978-94-010-2903-2

Gavilán, J. M., Barroso, R., Ariza, A., \& Sánchez, A. (2002). Laboratorio virtual de matemáticas II [Virtual laboratory of Mathematics II]. In J. M. Mesa, R. J. Castañeda, \& L. M. Villar (Eds.), La Universidad de Sevilla y la innovación docente, curso 2001-2002 (Vol. 1, pp. 77-85). Instituto de Ciencias de la Educación de la Universidad de Sevilla.

Gavilán-Izquierdo, J. M., Martín-Molina, V., GonzálezRegaña, A. J., Toscano, R., \& Fernández-León, A. (2019). Cómo construyen definiciones matemáticas los estudiantes para maestro: Una aproximación sociocultural [How pre-service teachers construct mathematical definitions: A sociocultural approach]. In E. Badillo Jiménez, N. Climent Rodríguez, C. Fernández Verdú, \& M. T. González Astudillo (Eds.), Investigación sobre el profesor de matemáticas: Práctica de aula, conocimiento, competencia y desarrollo profesional (pp. 135-155). Ediciones Universidad de Salamanca.

Güçler, B. (2013). Examining the discourse on the limit concept in a beginning-level calculus classroom. Educational Studies in Mathematics, 82(3), 439-453. https: / / doi.org/10.1007/s10649-012-9438-2

Heyd-Metzuyanim, E., Tabach, M., \& Nachlieli, T. (2015). Opportunities for learning given to prospective mathematics teachers: Between ritual and explorative instruction. Journal of Mathematics Teacher Education, 19(6), 547-574. https://doi.org/ 10.1007/s10857-015-9311-1

Hohenwarter, M., Borcherds, M., Ancsin, G., Bencze, B., Blossier, M., Elias, J., Frank, K., Gal, L., Hofstätter, A., Jordan, F., Konecny, Z., Kovacs, Z., Lettner, E., Lizelfelner, S., Parisse, B., Solyom-Gecse, C., Stadlbauer, C., \& Tomaschko, M. (2018). GeoGebra (version 5.0.507.0). http:/ / www.geogebra.org

Ioannou, M. (2018). Commognitive analysis of undergraduate mathematics students' first encounter with the subgroup test. Mathematics Education Research Journal, 30(2), 117-142. https: / / doi.org/10.1007/s13394-017-0222-6 
Lavie, I., Steiner, A., \& Sfard, A. (2019). Routines we live by: From ritual to exploration. Educational Studies in Mathematics, 101(2), 153-176. https://doi.org/ $10.1007 /$ s10649-018-9817-4

Martín-Molina, V., González-Regaña, A. J., \& GavilánIzquierdo, J. M. (2018). Researching how professional mathematicians construct new mathematical definitions: A case study. International Journal of Mathematical Education in Science and Technology, 49(7), 1069-1082. https://doi.org/10.1080/0020739X.2018.1426795

Nardi, E., Ryve, A., Stadler, E., \& Viirman, O. (2014). Commognitive analyses of the learning and teaching of mathematics at university level: The case of discursive shifts in the study of Calculus. Research in Mathematics Education, 16(2), 182-198. https:/ / doi.org/10.1080/14794802.2014.918338

Ouvrier-Buffet, C. (2011). A mathematical experience involving defining processes: In-action definitions and zero-definitions. Educational Studies in Mathematics, 76(2), 165-182. https://doi.org/ $10.1007 /$ s10649-010-9272-3

Rasmussen, C., Zandieh, M., King, K., \& Teppo, A. (2005). Advancing mathematical activity: A practice-oriented view of advanced mathematical thinking. Mathematical Thinking and Learning, 7(1), 51-73.

https:/ / doi.org/10.1207/s15327833mt10701_4

Sánchez, V., \& García, M. (2014). Socio-mathematical and mathematical norms related to definition in pre-service primary teachers' discourse. Educational Studies in Mathematics, 85(2), 305-320. https: / / doi.org/10.1007/s10649-013-9516-0

Sfard, A. (2007). When the rules of discourse change, but nobody tells you: Making sense of mathematics learning from a commognitive standpoint. The Journal of the Learning Sciences, 16(4), 567-615. https://doi.org/10.1080/10508400701525253

Sfard, A. (2008). Thinking as communicating: Human development, the growth of discourses, and mathematizing. Cambridge University Press. https:/ / doi.org/10.1017/CBO9780511499944

Stadler, E. (2011). The same but different-Novice university students solve a textbook exercise. In M. Pytlak, T. Rowland, \& E. Swoboda (Eds.), Proceedings of the Seventh Congress of the European Society for Research in Mathematics Education (pp. 2083-2092). University of Rzeszów and ERME.
Tabach, M., \& Nachlieli, T. (2015). Classroom engagement towards using definitions for developing mathematical objects: The case of function. Educational Studies in Mathematics, 90(2), 163-187. https://doi.org/10.1007/s10649-0159624-0

Thoma, A., \& Nardi, E. (2016). A commognitive analysis of closed-book examination tasks and lecturers' perspectives. In E. Nardi, C. Winsløw, \& $\mathrm{T}$. Hausberger (Eds.), Proceedings of the First Conference of the International Network for Didactic Research in University Mathematics (pp. 306-315). University of Montpellier and INDRUM.

Thoma, A., \& Nardi, E. (2018). Transition from school to university mathematics: Manifestations of unresolved commognitive conflict in first year students' examination scripts. International Journal of Research in Undergraduate Mathematics Education, 4(1), 161-180. https:/ / doi.org/10.1007/ s40753-0170064-3

Toscano, R., Gavilán-Izquierdo, J. M., \& Sánchez, V. (2019). A study of pre-service primary teachers' discourse when solving didactic-mathematical tasks. EURASIA Journal of Mathematics, Science and Technology Education, 15(11), em1762, 1-16. https://doi.org/10.29333/ejmste/108631

Viirman, O., \& Nardi, E. (2019). Negotiating different disciplinary discourses: Biology students' ritualized and exploratory participation in mathematical modeling activities. Educational Studies in Mathematics, 101(2), 233-252. https: / / doi.org/10.1007/s10649-018-9861-0

Weber, K., \& Mejia-Ramos, J. P. (2013). Effective but underused strategies for proof comprehension. In M. Martinez \& A. Castro Superfine (Eds.), Proceedings of the 35th Annual Meeting of the North American Chapter of the International Group for the Psychology of Mathematics Education (pp. 260-267). University of Illinois at Chicago.

Zandieh, M., \& Rasmussen, C. (2010). Defining as a mathematical activity: A framework for characterizing progress from informal to more formal ways of reasoning. The Journal of Mathematical Behavior, 29(2), 57-75. https:// doi.org/10.1016/j.jmathb.2010.01.001

Zaslavsky, O., \& Shir, K. (2005). Students' conceptions of a mathematical definition. Journal for Research in Mathematics Education, 36(4), 317-347.

\section{http://www.ejmste.com}

